\title{
Vinte Anos da Lei de Diretrizes e Bases da Educação Nacional (LDBEN)
}

\author{
Twenty Years of the Brazilian Educational Law (LDBEN)
}

\author{
Veinte años de la Ley de Directrices y Bases de la Educación \\ Nacional (LDBEN)
}

\section{Carlos Roberto Jamil Cury ${ }^{1}$}

\section{Resumo}

Este artigo coloca em tela os vinte anos de promulgação da Lei de Diretrizes e Bases da Educação Nacional (LDBEN), Lei 9.394/1996. Ao promover uma digressão histórica, o texto chama a atenção para a trajetória na educação brasileira de aspectos e princípios fundantes, a qual resulta no texto da lei atual. A análise mostra ainda a sucessão de alterações que recaíram sobre o texto aprovado em 1996, fruto do açodamento pela sua aprovação. Por fim, o artigo indica um conjunto de desafios para a legislação ampliar o reconhecimento e a efetivação do direito à educação no Brasil.

Palavras-chave: Legislação Educacional; Lei de Diretrizes e Bases da Educação Nacional; Lei 9.394/1996

\begin{abstract}
This article sets out the Brazilian National Education Law (LDBEN - Law 9.394/1996) twenty yearsanniversary. Promoting a historical digression, the text draws attention to the trajectory in Brazilian education of some aspects and founding principles, which results in the text of the current law. The analysis also shows the succession of changes that fell on the text approved in 1996, as a result of the rush of the proposal. Finally, the article indicates a set of challenges for the legislation to broaden the recognition and realization of the right to education in Brazil.

Keywords: Educational Legislation; Brazilian National Education Law; Law 9,394/1996.
\end{abstract}

\section{Resumen}

En este artículo se pone en la pantalla los veinte años de promulgación de la Ley de Directrices y Bases de la Educación Nacional (LDBEN), Ley 9.394/1996. Al promover una digresión histórica, el texto llama la atención sobre la trayectoria de algunos aspectos de la educación en Brasil y sus principios fundadores, que da lugar a la reciente ley. El análisis también muestra la secuencia de cambios que acontecieron sobre el texto aprobado en 1996, como resultado de la prisa para su aprobación. Por último, el artículo indica una serie de retos para la legislación para ampliar el reconocimiento y la realización del derecho a la educación en Brasil.

Palabras-clave: Legislación Educativa; Ley de Directrices y Bases de la Educación Nacional; Ley 9.394/1996 


\section{Introdução}

Fazer 20 anos? O que isto significa, além de uma data redonda? Se estivéssemos sob o Código Civil de 1916, a maioridade se atingiria aos 21 anos. Portanto, a comemoração seria mais pertinente daqui a um ano. Mas como já estamos sob o novo Código Civil da lei n. 10.406/2002 que dispôs a maioridade aos 18 anos, cumpre analisar os 20 anos sob o signo da maioridade.

Mas, afora esta provocação, o que significa, então, comemorar uma data redonda?

Ela é uma oportunidade para se refletir sobre uma lei importante como um momento de recuo na história da educação, quanto de uma visada da situação atual. Pelo recuo é oportuno rever caminhos feitos, uma espécie de balanço e, abastecidos por este dobrar-se sobre si mesmo (re-flexão), pensar no quadro atual e em perspectivas desafiadoras que mantenha caminhos exitosos já trilhados, repense vias derreadas e anuncie vias novas.

Um pequeno escorço histórico pode nos dar algumas perspectivas da manutenção de caminhos e da abertura de novas vias em prol da educação nacional.

\section{Notícia Histórica}

Aos 20 de dezembro de 1996, o presidente Fernando Henrique Cardoso sancionou a Lei de Diretrizes e Bases da EducaçãoNacional (LDBEN), denominada oficialmente Lei Darcy Ribeiro, sob o No. 9.394/96². Assinou junto com o Presidente, o ministro da Educação Paulo Renato Souza ${ }^{3}$.

O Diário Oficial da União a fez publicarem 23/12/96. Estamos, pois, perto de vinte anos dessa LDB.

Trata-se aqui de evocar não só conhecimentos relativos ao vintênio, mas também em reconhecer, a partir desse texto legal, alguns dos caminhos trilhados pela educação escolar brasileira.

Longo e polêmico foi o processo de tramitação legal dos projetos de LDBEN tanto no âmbito da sociedade civil, quanto no do legislativo e do executivo para que se chegasse a termo o mandado constitucional do art. 22, XXIV. Muitas foram as vicissitudes sofridas pelos diferentes textos que foram sendo escritos desde o início do processo legislativo ainda em 1988, por meio de muitas e variadas emendas aos projetos. Isso evidencia, de novo, como tem sido tradicional no Brasil, difícil e propriamente contencioso quando o assunto é um marco regulatório da educação escolar ${ }^{4}$.

Muitas foram também as avaliações relativas ao texto final da Lei com copiosa bibliografia a respeito 5 .

Ao lado dessa literatura, seria importante analisar a atuação de sujeitos coletivos, impossível no espaço desse esboço, como a do Conselho dos Secretários Estaduais de Educação (CONSED), o da União dos Dirigentes Municipais de Educação (UNDIME), o do Fórum dos Conselhos Estaduais de Educação e a da União dos Conselhos Municipais de Educação. Muitos outros sujeitos também se puseram a campo a fim de discutir os projetos e sugerir alternativas como é o caso dos Fóruns Estaduais em prol do Ensino Público, do Fórum Nacional do Ensino Público, da Confederação Nacional dos Trabalhadores da Educação, de associações profissionais de docentes, associações científicas, organizações não-governamentais e pesquisadores ${ }^{6}$.

2 A sanção presidencial representa a adesão do Chefe do Executivo ao projeto já aprovado pela Câmara e pelo Senado. A manifestação presidencial pelasanção positivaou pela sanção negativa (veto) significa uma forma co-participada entre os dois poderes no processo legislativo. Nesse sentido, a sanção ratifica a lei fazendo-a entrar em vigor. Trata-se de uma tradição no direito nacional e suaorigem tem a ver com a passagem das monarquias absolutas para as monarquias constitucionais. Cf. art. 66 da CF/88. Cf. CarvalhoNeto, 1992 e Silva, 1964.

3 De acordo, com 0 art. 87 da Constituição, os Ministros referendam atos presidenciais no âmbito de suaárea.

4 Cf. Buffa, 1979; Saviani, 1978, Britto, 1997

5 Cf. Castro 1998; Cury, 1997 e 2000; Demo, 1997; Frauches (org), 2000; Catani e Oliveira, 2.000 , Brzezinski, Iria (org.) 2003, Saviani, 2008, entreoutros.

6 Entrevistas com atores privilegiados, nesse processo, ainda estão por serem feitas. 


\section{E houve um antes remoto em vista de uma lei nacional da educação}

Nos marcos da Constituição Imperial de $1824^{7}$ e da Lei Geral da Educação de 15 de outubro de 1827, as primeiras letras, dispostas como direito dos cidadãos, vinham regradas com dispositivos válidos para todo o Império tais como salários de professor, concurso, currículo conquanto não se mencione financiamento específico. De acordo com o art. 15 e o art. 20 da lei de 1827, os sistemas provinciais (ou melhor: as redes de escolas de primeiras letras) tinham consistência precária e apenas teriam a plena "quando tiverem exercício os Conselhos Geraes..."

Já com o Ato Adicional de 1834, consoante o art. 10, a legislação sobre a instrução pública e estabelecimentos próprios a promovê-la fica como competência das Assembleias Provinciais, "não compreendendo as faculdades de Medicina, os cursos Jurídicos, Academias atualmente existentes e outros quaisquer estabelecimentos de instrução que para o futuro forem criados por lei geral".

Entra-se, pois, no que vem sendo chamado de dupla rede administrativa pela qual a instrução primária (primeiras letras) ficava sob responsabilidade direta das Províncias e das Câmaras Municipais, enquanto o ensino secundário e o superior, máxime este último, sob os poderes gerais. Mesmo assim, pelo art. 20, as leis provinciais deveriam passar pela Assembleia e Governo Gerais para verificar se estavam ou não conformes à Constituição.

Demandando um Ministério Especial da Instrução Pública, Bueno (1857) comenta o direito à educação na Constituição de 1824 e nas leis imperiais de então:

A instrucção primaria é uma necessidade, não desta ou daquella classe, sim de todas, ou de todos os indivíduos... É pois uma necessidade geral, e consequentemente uma divida da sociedade... Esta instrucção deve por isso mesmo não só ser gratuita mas também ser posta ao alcance de todas as localidades...0 art. $10 \S 20$ do acto adicional deu ás assembléasprovinciaes a faculdade de legislar a este respeito em relação ás respectivas provincias, e muitas dellas não se têm olvidado desse dever essencial. Entendemos, porém que os poderes geraes não devem de modo algum abdicar a attribuição que este mesmo paragrapho Ihes confere de concorrer de sua parte para tão util fim, e mui principalmente no intuito de crear uma educação nacional homogenea e uniforme, que gere e generalise o caracter brasileiro... (p. 440) (grifos adicionados)

A existência de um regime formalmente liberal, coexistente de modo esdrúxulo com o sistema de escravidão, aponta para um outro sentido da dupla rede, o social. Com efeito, a separação entre senhores e escravos, as dificuldades de acesso por parte de libertos, brancos livres não proprietários e as condições gerais do país faziam do limitado acesso à escolaridade uma barreira para maior parte da população. Neste sentido, podese dizer que, a despeito da educação ter sido proclamada direito dos cidadãos na Constituição, de fato ela consistia em um privilégio de poucos.

Entrementes, em que pese a contradição entre direito versus privilégio, a educação não deixou ser assinalada como um componente cultural para ordenar o conjunto das relações sociais à luz de declarações em prol de uma civilização nacional, racional, moral e religiosa no país.

Assim, o Decreto de 9 de dezembro de 1835, já sob o Ato Adicional de 1834, instrui, durante a Regência, os Presidentes das Províncias no sentido da boa execução da Lei de 14 de Junho de 1831 relativa às atribuições da Regência. Nelas, há a que aponta, entre as atribuições dos mesmos, no art. 18, as relativas a empregos. Nas orientações posteriores para o devido cumprimento da lei e deste artigo, pode-se ler no mesmo Decreto a proposta de um plano de educação uniforme em todo o país, a fim de promover a instrução e a moral:

$\S 12$. Satisfeitas as necessidades da administração que ficão indicadas, releva promover a instrucção e a moral, sem as quaes não ha civilisação, e muito menos liberdade. Um plano de educação, uniforme em todas as Provincias, que a torne nacional, que dê caracter, e particular physionomia ao povo brasileiro, é objecto de summa necessidade. Os principios que servem para o desenvolvimento da razão humana, e as principaes regras dos direitos e obrigações do homem, devem formar a base da instrucção geral. As maximas de conducta, prescriptas pelo Evangelho, e ensinadas pelos Ministros da Religião com a voz, e praticamente com o exemplo, serviráõ de

7 Cf. Chizzotti, in Fávero, 1996. 
alicerce á moral publica. Mas emquanto este plano se não póde realizar, convem ao menos que certo gráo de instrucção e moralidade seja um requisito indispensavel para a admissão dos empregos, no qual deverá sempre preferir o homem instruido e moral, e entre estes os casados, e os que fizerem as vezes de chefes de legitimas familias (grifo nosso).

À falta de um desejável e uniforme plano de educação, o critério de um certo grau de instrução associado à moral, deveria ser um requisito da seleção e da investidura de funcionários públicos.

O Decreto n. 1331. A de 1854, mais conhecido como Reforma Couto Ferraz, previa no seu art. 30 que incumbia ao Inspetor Geral do Império no § 50:

Coordenar os mapas e informações que os Presidentes das províncias remeterem anualmente ao Governo sobre a instrução primária e secundária, e apresentar um relatório circunstanciado do progresso comparativo neste ramo entre as diversas províncias e o município da Côrte, com todos os esclarecimentos que a tal respeito puder ministrar.

Já o Município da Corte abrigando o modelar Colégio de Pedro II deveria servir de referência para uma comparabilidade da instrução em curso nas províncias. Por exemplo, competia ao Inspetor Geral algo que, hoje, de modo muito mais complexo, é atribuição do Instituto Nacional de Estudos e Pesquisa Educacionais (INEP) ou seja a obrigação dos entes infranacionais de prestar determinadas informações ${ }^{8}$.

Mais do que isso, por longos anos, a organização pedagógica do Pedro II, seu currículo e até seu regimento servirão de marco para o conjunto da educação havida nas Províncias (depois Estados), tanto em estabelecimentos públicos como particulares para que seus certificados tivessem valor oficial. Este marco ficou conhecido como sendo o instituto da equiparação, inclusive para que os certificados tivessem valor oficial.

Este Decreto, porém, traz uma outra característica. O Estado não só passa a velar pela instrução pública como também volta a pôr sob sua supervisão os estabelecimentos particulares, de acordo com o art. 10 e art. 30 § 10 e § 3o. Observe-se que o §5o do art. 3o não especifica a instrução primária e secundária deixando implícito que se trata de toda ela. Mais enfática ainda é a lei ao reservar o Título IV e um Capítulo Único para o ensino particular com 15 artigos minuciosos.

Pode-se, pois, dizer que, pelo artigo 135, o da revogação das disposições em contrário, há a retirada da validade de um decreto de Dom João VI assinado às vésperas de seu retorno a Portugal. Com efeito, a Regência do ReinoPortuguês, na pessoa de D. João VI, pormeio de umDecreto assinado de 28 de Junho de 1821, permitiu a qualquercidadão, sem condicionalidades, o ensino e abertura de escolas de primeiras letras dentro de um clima ultraliberal.

Ao lado disto, na Assembleia Geral, houve propostas no sentido de indicar outros dispositivos para a educação. É o caso da obrigatoriedade.

Em sessão de 6 de agosto de 1870, por exemplo, o ministro dos Negócios do Império Paulino José Soares de Souza (filho), após considerar que o ensino primário

é aquele que desperta 0 maior interesse, por abranger todas as classes da população e tender à satisfação da primeira aspiração intelectual... e que em um país civilizado ninguém deve deixar de saber pelo menos ler e escrever...vou ao ponto de entender que os poderes públicos devem impô-lo como uma obrigação a todos os que estão na idade escolar...

A seguir afirma e propõe:

Se ha objeto, do qual devamos ir em auxílio das províncias é, sem contestação, o ensino público (Apoiados). Sempre entendi que a atribuição de legislar sobre instrução pública não é exclusiva das assembléias provinciais e que o encargo que tem pesado unicamente sobre as províncias de promoverem o ensino, pode ser partilhado pelo Estado, que as deve auxiliar nesta parte, logo e quando lhe for possível (Muitos apoiados) (p. 72-73).

Ao lado desta proposta de um proto regime de colaboração, interpretando o Ato Adicional, Paulino de Souza refere-se aos poderes gerais como competentes para atuar no ensino primário por meio de lei geral e conclui que esta atribuição é cumulativa. ...

8 Cf. lei n. 9.394/96, art. 9o V e VI e também art. 87. 
Não compreendí em nenhuma das três esferas o ensino público porque, em minha opinião, tanto o Estado, como a Província, como 0 Município devem promovê-lo (Apoiados) (p.74).

Ponto importante foi a proposta da obrigatoriedade vinda de dispositivo presente na outra reforma educacional do Império: a Reforma Leôncio de Carvalho, no Decreto 7247 de 19 de abril de 1879. Seu artigo 2o incluía penas para os pais ou tutores que deixassem de cumprir tal obrigação nas escolas públicas ou particulares ou por meio de instrução em casa.

Outra disposição constante desta Reforma se lê no art.80 em vários de seus parágrafos. 0 parágrafo 20 possibilita a subvenção nas localidades afastadas, inclusive para as províncias e para as escolas particulares que inspirem a necessária confiança caso acolham .

A possibilidade de equiparação das escolas normais particulares com as escolas normais oficiais está no parágrafo 6o. Tal permissão valeria para as escolas secundárias que adotassem o mesmo programa de estudos do Colégio de Pedro II, observadas outras condicionalidades postas no parágrafo 80. E o parágrafo 9o possibilitou o auxílio dos poderes gerais na criação de escolas profissionais. Também o parágrafo 10o punha sob os poderes gerais a fundação de bibliotecas, museus pedagógicos onde houvesse escolas normais e, no parágrafo 110 torna-se papel dos poderes centrais criar ou auxiliar nas províncias bibliotecas populares.

Pelo menos do ponto de vista formal, alguns pontos necessários para um plano de educação vão se delineando: a gratuidade, a obrigatoriedade, o papel de monopólio do Estado na atribuição de graus escolares e acadêmicos e a relação público/privado na Corte, nas Províncias e a oferta de insumos pedagógicos extraescolares. Estes pontos, pelo ordenamento jurídico, se compuseram com o fim do regime escravocrata em 1888, ou seja, a partir deste ato, ainda sob o Império, a cidadania jurídica se alargou.

Pode-se dizer que residem aqui, ainda que não em estado pleno, aquelas leis que viriam a ser as de diretrizes e bases da educação nacional.

A República não registrou na Constituição de 1891 a gratuidade em nível nacional, presente no texto constitucional do Império, manteve porém o papel do Estado ao não abdicar do ensino oficial ${ }^{9}$. Tal dispositivo deixaria a critério dos Estados, segundo art. 50 da Constituição, o da autonomia federativa, a previsão da gratuidade e da obrigatoriedade.

Registre-se que a República não alterou significativamente a dupla rede que vinha do Império, dado o quadro sócio-econômico excludente. Uma exceção se verificou quando durante e após a primeira Guerra houve oficialização e financiamento das escolas primárias em núcleos coloniais de população imigrada ${ }^{10}$. Contudo, se a gratuidade da instrução primária ficou por conta daquela autonomia dos Estados, por outro lado, o Estado Nacional impôs a laicidade nos estabelecimentos públicos consoante o art. 72, §6o.

Dois registros são dignos de assinalação: o crescimento da importância do Colégio Pedro II (por um tempo denominado Ginásio Nacional) nos processos de equiparação e algumas iniciativas tendentes a inserir a União em um papel mais ativo. No primeiro caso, a equiparação fornecida pela União de certo modo validava nacionalmente um certificado ou diploma. Esta equiparação continuava tendo como condicionante o aceite do currículo e dos aspectos gerais do regulamento do Pedro II. No segundo caso, tome-se como exemplos de uma e outra situação a Conferência Interestadual do Ensino primário e a Reformas João Alves/ Rocha Vaz de 1925.

A Conferência Interestadual do Ensino Primário em 1921, sob a Reforma Carlos Maximiliano, tendo com fundo as Ligas Nacionalistas, as estatísticas relativas à instrução primária, o apontamento da responsabilidade da União em acabar com o analfabetismo, foi convocada pelo governo da União para que, junto com os Estados,

\section{Cf. Cury, 2001.}

10 Temos aqui a primeira intervenção direta e financiada da União no ensino primário, por meio do Ministério da Justiça, nos Estados do Paraná, Rio Grande do Sul e Santa Catarina, respectivamente, mediante os Decretos : n.13.175 de 6/9/1918, n. 13.390 de 8/1/1919 e n. 13.460 de 5/2/1919. 
se pudesse estabelecer diretrizes e ações em vista de uma ação conjunta. De acordo com o estudo precioso de Nagle ${ }^{11}(1974)$ lê-se a este respeito:

....as medidas que a União deveria estabelecer com os Estados seriam, em síntese, as seguintes: nacionalizar e tornar obrigatório e homogêneo 0 ensino primário, subvencionar as escolas nos Estados, criar o fundo escolar e fornecer material escolar a esse ensino, quando subvencionado (p. 136).

Segundo este mesmo autor esta Conferência "não produziu os frutos desejados, principalmente pela falta de recursos financeiros" (p. 139).

A Reforma João Alves/Rocha Vaz de 1925 manteve o ensino oficial (que havia sido desoficializado na Reforma Rivadávia Corrêa de 1911) e transmudou o ConselhoSuperior de Ensino (1911) em Conselho Nacional de Ensino no interior do qual haveria o Departamento Nacional de Ensino como órgão executivo do Conselho Nacional de Ensino e como "centro coordenador" que supervisionasse a autonomia das instituições escolares ${ }^{12}$.

Debalde a Revisão Constitucional de 1925/1926 tentou restabelecer, em nível nacional a gratuidade (disposta na Constituição Imperial de 1824) e estabelecer a obrigatoriedade no ensino primário ${ }^{13}$.

Importante papel cumpriram as Reformas Estaduais dos anos vinte que promoveram não só a introdução de novos métodos de ensino, como procuraram também aumentar as oportunidades de acesso nas escolas públicas ${ }^{14}$.

A Revolução de Trinta, deflagrada em 03 de Outubro de 1930, levou Getúlio Vargas ao poder como Chefe do Governo Provisório em 03 de novembro de 1930. O Ministério dos Negócios da Educação e Saúde Pública foi criado em 14 de Novembro de 1930, pelo Decreto n. 19.402, vale dizer 11 dias após a posse de Vargas. Seu primeiro titular foi Francisco Campos. Dotado de grande iniciativa e apoiado por Vargas, estabeleceu as atribuições do MESP pelo Decreto n. 19.560/31; criou o Conselho Nacional de Educação pelo Decreto n. 19.580/31; dispôs sobre o Ensino Superior e Universitário pelo Decreto n. 19.581/31 e sobre o ensino secundário pelo Decreto n. 19.890/31; instituiu o ensino religioso facultativo pelo Decreto n. 19.941/31, entre outros.

De todo o modo, a dimensão nacional começa a despontar. Uma delas é o Conselho Nacional de Educação (CNE), criado pelo Decreto n. 19.850, de 11 de abril de 1931. Precedido por Conselhos de Instrução Superior no Império e também na República e pelo Conselho Nacional de Ensino, a partir de 1925, ao CNE coube como atribuição sua, sob o art. $5^{\circ}$ do Decreto, algo que, no seu conjunto, poder-se-ia denominar de Plano Nacional de Educação. A ele cabia o estabelecimento das diretrizes de toda a educação, inclusive primária e a ampliação de recursos financeiros para tal.

Como consequência dessas atribuições, na sessão do Conselho de 27 de junho de 1931, o conselheiro João Simplício Alves de Carvalho apresentou proposta de criação de uma ou mais comissões para o preparo e a redação de um plano nacional de educação a ser submetido ao Governo da República e dos Estados. Em 27 de junho de 1931, João Simplício Alves Carvalho apresentou duas propostas, sendo uma delas referente ao PNE:

Proponho que 0 Conselho Nacional de Educação,... designe uma ou mais comissões para o preparo e a redação de um plano nacional de educação, que deve ser aplicado e executado dentro de um período de tempo, que nele será fixado. Esse plano procurará satisfazer as exigências da atualidade brasileira, tomando em consideração as condições sociais do mundo, e assegurará, pela sua estrutura e pela sua aplicação, 0 fortalecimento da unidade brasileira, o revigoramento racial de sua gente e o despertar dos valores indispensáveis ao seu engrandecimento econômico; e, depois de estudado e aprovado pelo Conselho Nacional de Educação, será submetido ao exame do Governo da República e á consideração dos Governos dos Estados. E estabelecerá, apanhando todos os aspectos do problema educativo... ${ }^{15}$ (grifos adicionados)

11 Nagle, Jorge. Educação e Sociedade na primeira República. São Paulo : EDUSP, 1974.

12 De algum modo, o Conselho e o Departamento vão criar as condições internas para sua transmutação em Conselho Nacional da Educação e Ministério da Educação, no início dos anos Trinta.

13 Cf. Cury, 2003.

14 Cf. Nagle, 1974.

15 Cury, 2013. 
Esta demanda, como se viu, já vinha do Império e dos anos 20. Mas tal empenho ganhará força e maior visibilidade por meio dos esforços e pressão de vários grupos, especialmente aquele articulado em torno da Associação Brasileira de Educação e a publicação do Manifesto dos Pioneiros da Educação Nova de 1932.

O Manifesto de 1932 entende que um dos pilares da reconstrução nacional teria que ser por meio de um plano de reconstrução educacional. Diz ele a esse respeito:

No entanto, se depois de 43 annos de regimen republicano, se dér um balanço ao estado actual da educação publica, no Brasil, se verificará que, dissociadas sempre as reformas economicas e educacionaes, que era indispensavel entrelaçar e encadear, dirigindo-as no mesmo sentido, todos nossos esforços, sem unidade de plano e sem espirito de continuidade, não lograram ainda crear um systema de organização escolar, á altura das necessidades modernas e das necessidades do paiz (p. 33).

No mesmo ano de 1932, na V Conferência Nacional de Educação, realizada em Niterói, a promotora do evento - a ABE - põe como objetivo da mesma sugerir, no anteprojeto de Constituição da Assembleia Nacional Constituinte de 1933, um plano de educação nacional.

Assim, como desfecho deste processo, a Constituição de 1934 abrirá um capítulo próprio da educação. Nele, vários dispositivos concorreram para que a educação tivesse um perfil nacional tais como a gratuidade, a obrigatoriedade, a vinculação de impostos para a área, o plano nacional de educação a ser elaborado pelo Conselho Nacional de Educação. Coube à União, como competência privativa, pelo art. 50 XIV, o traçar as diretrizes da educação nacional. Estas seriam de competência privativa do poder legislativo por conta do art. 39, n. 8, letra e, porém com sanção presidencial. Já o inciso XIX, letra I, do art. $5^{\circ}$. não impede à União o legislar sobre a instrução. Contudo, o $\S 3^{\circ}$ do art. $5^{\circ}$, face ao inciso XIV, não exclui a legislação estadual supletiva ou complementar sobre as mesmas matérias.

Nesta Constituição, contudo, faculta-se, no art. 9o "à União e aos Estados celebrar acordos para a melhor coordenação e desenvolvimento dos respectivos serviços, e, especialmente, para a uniformização de leis..."

Apesar de tais avanços, certamente significativos e até hoje bandeiras de uma educação como direito juridicamente protegido, os anos 30 e 40, além da dupla rede administrativa e da dupla rede social, vai conhecendo contornos mais nítidos na dimensão social pela distinção entre público e privado.

Veja-se, por exemplo, quando da tramitação do Plano Nacional de Educação de 1936/37 na Câmara dos Deputados, o seguinte trecho de um discurso de Raul Bittencourt, deputado e relator da Comissão Especial relativa a este Plano:

A par da democracia, a Carta de 1891 consagrava a Federação, os Estados autônomos, com liberdade relativa, sujeitos a princípios gerais, e só a União soberana. Quando se tratava da educação primária, entretanto, os Estados se comportavam como nações livres e quando consideravam os problemas do ensino secundário e superior os Estados eram reduzidos a departamentos de um governo central, como se fôramos uma República Unitária (Diário do Poder Legislativo de 24/8/1937, p. 39889).

Contrastando com essa prática dualista advinda da Carta de 1891, o deputado afirma o caráter federativo da organização política brasileira da Constituição de 1934 e do Capítulo sobre a educação.

O golpe que conduziu ao Estado Novo teve repercussões na educação, especialmente o fim da vinculação, os privilégios da rede privada e a censura aos livros ${ }^{16}$.

Mesmo não tendo conseguido levar a diante o projeto de um Código da Educação, em 30 de janeiro de 1941, Vargas e Capanema convocam, via Decreto n. 6.788, a chamada 1a. Conferência Nacional de Educação e de Saúde em vista de uma organização e de um programa nacional de educação.

A redemocratização trouxe a Constituição de 1946 e com ela seu art. 5o, XV, d, o das diretrizes e bases da educação nacional como competência privativa da União, bem como vários dispositivos de 1934 no capítulo da educação como gratuidade, obrigatoriedade e vinculação de impostos.

A lei de diretrizes e bases da educação nacional, sancionada em 1961, após 13 anos de tensa tramitação na sociedade civil e no Congresso, impôs para todos os sistemas 5 disciplinas obrigatórias para o ensino

16 Horta, 1994. 
secundário pelo § 10 do art. 35 e apontou para um sistema geral de educação quando tratou da educação dos excepcionais. No art. 92, atribui-se ao Conselho Federal de Educação a incumbência de elaborar o plano de educação aplicável a cada um dos Fundos de Educação: o do ensino primário, o do ensino médio e o do superior.

A ditadura militar de 1964 impôs novos percalços para a educação como a censura e a perseguição a dissidentes. A Carta de 1967, já sob o golpe civil-militar de 1964, suprimiu a vinculaçãoentre o financiamento da educaçãoescolar e a porcentagem da receitaresultante de impostos arrecadados ${ }^{17}$, ao mesmo tempo que ampliou a obrigatoriedade do ensino primário para 8 anos e determina a competência privativa da União (art. 80, XIV) em estabelecer planos nacionais de educação e de saúde e diretrizes e bases da educação nacional (XVII, q).

As consequências da ditadura se fizeram presentes na alteração da lei n. 4.024/61 pela lei n. 5.692/71 e pela lei n. 5.540/68 e, especialmente, sobre o conjunto dos docentes em seus salários e carreiras.

O retorno da obrigatoriedade de recursos para a educação constitucionalmente posta só veio mediante a emenda Calmon, emenda n. 24/83 regulamentada pela lei n. 7388/85.

\section{E houve um Antes próximo da sanção da Lei}

O capítulo da Educação na Constituição de 1988 representou um significativo avanço para a área ${ }^{18}$. Por outro lado, como uma nova LDB era mandato constitucional a ser efetivado, havia uma coexistência entre o avanço propiciado pela Constituição e o texto da Lei n. 4.024/61 com a redação dada pela Lei n. 7.044/82 e da Lei n. 5.540/68.

Também há de assinalar a Lei n. 9.131/95, a Lei 9.192/95 e, de modo especial, para a educação básica, a Lei n. 8.069/90 mais conhecida como Estatuto da Criança e do Adolescente (ECA). A primeira (re)cria o Conselho Nacional de Educação com suas atribuições e estabelece um sistema nacional de avaliação da educação ${ }^{19}$. A outra estabelece procedimentos para eleições de dirigentes no sistema federal de educação. O ECA, enfim, contém uma retomada do capítulo de educação da CF/88 nos princípios e em aspectos pedagógicos importantesnão explicitamente postos na LDBEN que viria a ser a Lei n. 9.394/96.

Havia, pois, face ao capítulo constitucional da Educação, uma coexistência formada por concepções, ao mesmo tempo distintas e convergentes, resultando ora em recepções juridicamente válidas, ora em um hibridismo, ora em "buracos negros" e mesmo em revogações. De todo modo, havia uma coexistência entre o "novo e o velho" sugerindo dificuldades de hermenêutica quanto a vários pontos na busca de uma continuidade jurídica viável.

Tal é o caso da nomenclatura da organização da educação, como ensino fundamental e médio versus ensino de primeiro grau e de segund ograu; também se apresentam questões relativas aos princípios da gratuidade, da gestão democrática, da valorização do magistério e do padrão de qualidade, entre outros. E surge a imposição constitucional de novos deveres ao Estado como são os casos da educação infantil, do direito público subjetivo e dos conteúdos curriculares mínimos (ao invés de currículo mínimo) e do regime de colaboração. Outros pontos importantes se referem ao estatuto do sistema privado, ao acolhimento de novidades como a distinção entre língua oficial e língua materna no ensino, aos novos percentuais de vinculação e ao acolhimento do sistema municipal de educação autônomo.

17 A vinculação retornou apenas para os Municípios, na emenda da Junta Militar de 1969 e fora do capítulo da educação ou seja no art. 15, §3o letra f. 18 Cf. Maliska, 2001; Cury, 1989; Farenzena, 2006.

19 Cf. Belloni, 2003, Nunes, parte III, 22012. 
Sobre essas congruências e incongruências, Bobbio (1994) sustenta:

0 fato de o novo ordenamento ser constituído em parte por normas do velho não ofende em nada o seu caráter de novidade: as normas comuns ao velho e ao novo ordenamento pertencem apenas materialmente ao primeiro; formalmente, são todas normas do novo, no sentido de que elas são válidas não mais com base na norma fundamental do velho ordenamento, mas com base na norma fundamental do novo. Nesse sentido falamos de recepção, e não pura e simplesmente de permanência do velho no novo. A recepção é um ato jurídico com 0 qual um ordenamento acolhe e torna suas as normas de outro ordenamento, onde tais normas permanecem materialmente iguais, mas não são mais as mesmas com respeito à forma (p. 177).

Nessa situação, havia que fazer convergir "matéria e forma" em razão do e em adequação ao novo ordenamento trazido pela Lei Maior.

Isso tudo, de um lado, gerava a expectativa com relação a uma nova LDB e, de outro lado, por força do art. 25 do ADCT, a partir de 180 dias da promulgação da CF/88 ficavam revogados "todos os dispositivos legais que atribuam ou deleguem a órgão do Poder Executivo competência assinalada na Constituição..."20

Analisando esse artigo, diz Ranieri (2000):

... 0 artigo 48, caput, da ConstituiçãoFederal determina que cabe ao Congresso Nacional dispor sobre todas as matéria de competência da União; e a Lei n. 4.024/61 atribuía, efetivamente, competências normativas ao CFE (artigo 9º). Não tendo sido tal prazo prorrogado por lei, nem editada nova lei específica atribuindo aquelas competências, o CFE até a sua extinção, provocada pela Lei n. 9.131/95, atuou sem competência legal, o que, a rigor, implica a nulidade dos atos normativos praticados no período (p. 163).

A chegada da Lei n. 4.024/61 com a redaçãodada pela Lei 9.131/95 formaliza o Conselho Nacional de Educação (CNE), dada a extinção do Conselho Federal de Educação ${ }^{21}$. Com isso, ressurge um órgão legal para interpretar as leis educacionais e propiciar a continuidade da ordem jurídica e capaz de arbitrar o andamento dos sistemas de educação²2.

Ao mesmo tempo, ainda estava em curso o processo de elaboração da nova LDB conducente à solução do caráter híbrido existente e à conformação de coerência à CF/88. E, nesse processo, projetos distintos disputavam a hegemonia na explicitação de princípios gerais postos na Constituição.

Os projetos existentes disputaram acirradamente o campo civil e parlamentar, sendo o projeto provindo da Câmara bem mais analítico e o outro, advindo do Senado, bastante sintético. O termômetro capaz de medir a temperatura de ambos era dado pelo maior ou menor "calor" da intervenção do Estado na educação escolar, seja na administração pública, seja no segmento privado. E esse termômetro passou a subir tanto mais quanto mais o governo eleito em 1994 e empossado em 1995 não só fizera clara opção pelo projeto sintético, como aderiu à vaga conservadora de vários regimes políticos existentes, inclusive na América Latina ${ }^{23}$.

Apesar dessa vaga conservadora poder propor leis regulamentadoras que contivessem dispositivos também conservadores, não se pode deixar de apontar o papel amortecedor de vários artigos da Constituição de 1988 cujo teor mais permanente tornaram, no âmbito da educação, menor o impacto das políticas restritivas aos direitos sociais e outras tendentes à saída do Estado de atividades econômicas.

20 Cf. Decreto n. 1734/95.

21 Cf. MedidaProvisória n. 661 de 18/10/1994 e seguintesaté à MP n. 1126 convertida na Lei n. 9131/95.

22 Menos do queantecipar a LDB, a lei n. 9.131/95 foi uma espécie de lei-ponte do tipo regulamentação préviadentro de uma previsibilidade de que 0 projetosintético seria aprovado.

$23 \mathrm{Um}$ aspecto importante desta vaga foi a lei n. 9.131/95 e o dispositivo da avaliação externa dos estabelecimentos escolares e a redefinição do Pacto Nacional pela Valorização do Magistério e Qualidade da educação em favor dos termos do FUNDEF, lei n. 9.424/96. Assinado em 1994, por representantes do Ministério da Educação e dirigentes de entidades educacionais, o pacto previa um salário mensal de $\mathbf{R} \$ 300$, em valores de julho daquele ano. 0 pacto de 1994 foi subscrito pelo então ministro da Educação, Murílio Hingel, e pelos presidentes do Conselho de Reitores das Universidades Brasileiras (Crub), José Carlos de Almeida; do Conselho Nacional dos Secretários de Educação (Consed), Marcos José de Castro Guerra; da União Nacional dos Dirigentes Municipais de Educação (Undime), Maria Helena Guimarães; do Fórum Nacional dos Conselhos Estaduais de Educação (FNCE), lara Sílvia Wortmann, e da Confederação Nacional dos Trabalhadores na Educação (CNTE), Horácio Francisco dos Reis Filho. 


\section{Uma redação final apressada}

A redação final da LDB, obediente por princípio à CF/88, teve uma sofrida solução com a sanção da Lei n. 9.394/96 tornando-se, de fato e de obrigação legal, um campo obrigatório de referência educacional.

A opção pelo projeto sintético, ainda que jungido de aspectos provindos do projeto analítico, se deu também dentro de uma educação escolar nacional complexa (para efeito de sua administração, gestão, financiamento e controle $)^{24}$. Imprecisões terminológicas reforçaram a necessidade de uma hermenêuticaque viabilizasse o novo texto legal 25 .

Essas dificuldades associadas à inevitável postulação de grupos interessados em alterar aspectos específicos da lei recém-aprovada, conduziram, nesses vinte anos, a 40 alterações sob a forma de leis no no corpo legal da lei então sancionada.

Desse modo, no interior dessas 40 leis, habitam 178 mudanças inclusive com alterações das alterações.

São 47 Decretos regulamentadores. Se somarmos as leis (40) com os decretos (47) temos um total de 87 alterações. Se tomarmos o conjunto das alterações processadas pelas 40 leis mais os decretos, teremos uma soma de 225 alterações.

Uma tal quantidade de alterações (87), praticamente $89 \%$ do texto, conquanto possível em qualquer lei, é indicativa de que algo poderia ter sido melhor redigido na versão original. Mas se considerarmos as 178 alterações legais com o seu impacto sobre os artigos, teremos 193\% de mudanças ${ }^{26}$.

São mudanças de toda a ordem: acréscimo de componente curriculares, ampliação da obrigatoriedade, introdução de dias comemorativos, redefinição da educação profissional, conceituação de profissional da educação, entre outros.

Um ponto a ser destacado na LDB é a maior consciência e presença do direito à educação infantil e o direito à diferença. A LDB, apoiada na Constituição, passou a reconhecer, diria Bobbio (1992) direitos de especificação tais como os relativos às fases da vida, às pessoas com deficiência, às populações indígenas e negras entre outros ${ }^{27}$.

Além disso, há que se assinalar outras leis concorrentes e complementares à própria educação escolar derivadas ou não de emenda constitucional passaram a ser de domínio conexo. No primeiro caso, pode-se citar, como paralelas e concorrentes à LDBEN, também as leis n. 10.436/02 (língua de Libras), a 11.161/05 (língua espanhola) e a lei n.11.738/2008 do piso salarial profissional nacional dos professorado do magistério público da educação básica.

Relativamente ao EnsinoSuperior temos a Lei do Sistema Nacional de Avaliação da Educação Superior, lei n. 10.861/04 (Lei do SINAES) que redefine artigos da Lei n. 9.131/95 e tem o seu complemento na Portaria MEC n. 2.051/04 regulamentando a figura do Conselho Nacional da Avaliação da Educação Superior(CONAES). A Lei n. 11.096/05 do Programa Universidade para Todos (PROUNI) e suas respectivas regulamentações por Portaria ou Decreto também significam uma alteração significativa nas relações público/privado. A Portaria MEC n. 2.051/04 regulamenta a lei do SINAES e o Decreto n. 5.245/04 regulamenta o PROUNI28.

24 A referênciaaqui é à complexidade nãosó de um país continental e diverso, como também dos delineamentos do pacto federativo.

25 Atribuem-se tais imprecisões ao afã de prestigiar em vida 0 antropólogo Darcy Ribeiro, autor do projeto do Senado. Coube ao Conselho Nacional de Educação regulamentar esta nova legislação por meio de Pareceres e Resoluções. Esta atividade normativa importa muito na interpretação da lei.

26 Esse volume de alterações parece indicar um processocontínuo, quase que permanente, de atividade propriamente legiferante de educação devido ao próprio caráter sintético da LDBEN aprovada. Isso obriga os executivos, em rotatividade política, a alterar o ordenamento legal para poder levar adiante programas de governo. Cf. Couto, 1997.

27 Cf. Parecer CNE/CEB 17/01, Res. 02/2001 e Res. CNE/CEB 01/04 e CURY, 2005.

28 Nessas matérias, houve significativa normatização desses assuntos no ConselhoNacional de Educação. 
Mediante o Decreto 6.096, de 24 de abril de 2007, com o objetivo de dar às instituições condições de expandir o acesso e garantir condições de permanência no Ensino Superior, foi criado o Programa do Governo Federal de Apoio a Planos de Reestruturação e Expansão das Universidades Federais Brasileiras (REUNI).

Ao lado da ampliação do acesso, com o melhor aproveitamento da estrutura física e do aumento do contingente de recursos humanos existente nas universidades federais, está também a preocupação de garantir a qualidade da graduação da educação pública.

Paralelamente, um esforço para criar um marco regulatório no âmbito da inovação tecnológica, por meio de incentivos relativos ao ambiente produtivo, foi a aprovação da Lei n. 10.973/0429.

Tangente à pós-graduação, deve-se destacar a existência do Plano Nacional de Pós-Graduação: 2005-2010 e do de 2011-2020.

Em virtude da emenda 14/96, a do FUNDEF foram modificados artigos importantes do capitulo da educação da Constituição Federal. Do conjunto dessa emenda procedeu a Lei n. 9.424/96 sancionada a 24 de dezembro de 1996, publicada no DiárioOficial de 26/12/1996, mais conhecida como a Lei do FUNDEF.

A lei do FUNDEF, para efeito de políticas educacionais do ensino fundamental, em matéria de financiamento, teve um impacto tão grande ou maior do que a própria LDB. Afinal, ela tange ao mesmo tempo o pacto federativo e o sistema de financiamento do ensino obrigatório seja pela sub-vinculação, seja pelo maior controle dos recursos destinados à manutenção e desenvolvimento da educação.

Já em respeito ao art. 214 da Constituição, tem-se a Lei n. 10.172/01, mais conhecida como Plano Nacional de Educação (PNE). Sua tramitação revelou a reedição da concepção de participação dos dois projetos: o do executivo, mais sintético, menos abrangente e mais restrito na sua elaboração, e o da sociedade civil maisanalítico, mais abrangente que contou com ampla participação em especial a partir dos Fóruns Estaduais e do Fórum Nacional em defesa da Escola Pública. A lei aprovada no Congresso, a rigor uma expressão continuada da LDBEN em matéria de metas, objetivos e financiamento, apresentou um realismo no diagnóstico da educação nacional e teve sua eficácia dependente, em maior parte, do financiamento. Contudo, esse último ponto, ao ser sancionada a lei, sofreu vetos presidenciais. Eles significaram uma perda substantiva quanto ao caráter obrigatório do Plano podendo-se dizer que ele, praticamente, se tornou um Plano declaratório.

A emenda constitucional n. 53/2006, ainda sobre o art. 214 da Constituição, substituiu a emenda 14/96 e cria o Fundo de Manutenção e Desenvolvimento da Educação Básica e Valorização dos Profissionais da Educação (FUNDEB) e cuja lei regulamentadora é lei n. 11.494/2007. Ambas com grande impacto sobre o conjunto da educação básica.

Mais recentemente, em 11 de novembro de 2009, o Congresso Nacional aprovou a Emenda Constitucional 59. Esta trouxe importantes modificações no capítulo da Educação da Constituição da República de 1988. Por meio dessas alterações, a educação básica obrigatória e gratuita passou a vigorar como direito público subjetivo para faixa etária de 4 a 17 anos, o atendimento ao educando, em todas as etapas da educação básica, deve contar com os vários programas suplementares como material didático-escolar, transporte, alimentação e assistência à saúde.

Por outro lado, o art. 214, ora emendado pelo mesmo dispositivo supracitado, estabeleceu, em seu inciso VI, que a meta de aplicação de recursos públicos em educação deverá ter o Produto Interno Bruto (PIB) como referência proporcional. Tal medida confere com a ampliação de responsabilidades por parte dos entes federativos, especialmente com a da faixa etária ínsita na emenda. Ora, em função disso tudo, a universalização do ensino obrigatório deverá contar necessariamente com formas de colaboração entre todos os sistemas de ensino dos entes federativos.

$29 \mathrm{Em} \mathrm{15/10/06,} \mathrm{o} \mathrm{Executivo} \mathrm{encaminhou} \mathrm{ao} \mathrm{Congresso} \mathrm{projeto} \mathrm{de} \mathrm{lei} \mathrm{que} \mathrm{altera} \mathrm{e} \mathrm{promove} \mathrm{a} \mathrm{lei} \mathrm{de} \mathrm{incentivos} \mathrm{fiscais,} \mathrm{lei} \mathrm{n}$. 11.196/05, beneficiando as pessoas jurídicas que aplicarem em pesquisas científicas e tecnológicas de acordo com a lei n. 10.973/04. 
Mais do que isto, os sistemas existentes contarão doravante com um inédito sistema nacional de educação. Esse desfecho, inédito em nossa história da educação, patenteia uma realidade que, embora latente, jamais havia sido explicitada em nossa evolução de políticas públicas. Tal desfecho comunga com vários dispositivos da Constituição de 1988, da legislação infraconstitucional, especificamente com a aprovação da lei n. 13.005/2014 e com o anseio de muitos educadores que viam nesse sistema o aumento do asseguramento e da garantia do direito à educação.

Pode-se afirmar, doravante, o sistema nacional de educação existe como conceito e como positivação jurídica. Ou seja, após sua tramitação, aprovação e sanção de acordo com o processo legislativo, o sistema nacional de educação passou a existir juridicamente e, vigente e em vigor, se torna de observância obrigatória, dado que aprovado por amplo consenso nas casas legislativas do Congresso Nacional.

\section{Desafios}

Um primeiro desafio é a congruência do SNE com a LDB. Afinal, se o Sistema já existe por mandamento constitucional, em que ele realmente consiste? A pergunta que se faz, nesse momento, à vista do art. 13 da lei n. 13.005/2014, é: qual é ou será sua composição/organização para que a consistência tenha a devida eficácia? Pois a eficácia, complementar à vigência, é tanto aquela que produz efeitos jurídicos mediante regulamentações de situações pertinentes ao assunto, como aquela denominada de efetividade que outra coisa não é senão a realização da norma em termos de sua concretude sociopolítica. O valor proclamado e positivado como dever ser (existir), então, torna-se um ponto de partida de valor afim de que se aproxime ou mesmo se confunda com o valor consistente no ser da realidade (consistir).

Nesta lei, há a criação de uma nova arena educacional do regime de cooperação, estabelecida pelo § 50 do art. 7o da lei n. 13.005/14: a instância permanente de negociação e cooperação entre a União, os Estados, o Distrito Federal e os Municípios. Entre coisas outras desta nova instância cabe "pactuar entre União, Estados, Distrito Federal e Municípios...a implantação dos direitos e objetivos de aprendizagem e desenvolvimento que configurarão a base nacional comum curricular do ensino fundamental. O mesmo se dá com o ensino médio e com a qualidade".

Outro desafio é o da sustentabilidade financeira do Plano. Há a tormentosa questão do financiamento a qual, se em tempos de bonança econômica já era complexa, em tempos de crise, além de complexa se torna complicada.

A referência ao PIB (chegar aos 10\% em dois tempos) é muito clara na emenda constitucional e na própria lei n. 13.005/2014. Tal sustentabilidade é crucial. Esta cláusula constitucional é condição de possibilidade para sucesso do PNE. Sua não efetivação será mais um retorno ao fracasso dos PNE passados (1936/37; 1961/62 e 2001-2011).

Entretanto é preciso fazer uma anatomia do que significa Produto Interno Bruto (PIB). O PIB é um indicador macroeconômico medindo o crescimento (ou não) da atividade econômica de um território ou de uma região ${ }^{30}$. Neste sentido, ele pode variar muito para cima ou para baixo de um ano para outro. Mas fique claro que PIB não é moeda, mas referência de atividade econômica ${ }^{31}$.

E, até por relação direta com este desafio, outro, urgente e difícil, e de responsabilidade final do Conselho Nacional de Educação: a elaboração do Parecer e da Resolução referidos à Base Nacional Comum Curricular.

300 PIB - 2014 no Brasil foi de 5,52 trilhões, sendo o PIB per capita de 27.230,00.

31 Neste momento crucial de nossa história política, na vigência de um governo de facto (não de iure), as perspectivas são as mais desalentadoras com os planos sugeridos de retorno da desvinculação dos recursos da União (DRU) e outros até piores como o texto denominado "ponte para o futuro" (sic ?) em que a desvinculação total é anunciada. 0 passado da desvinculação (1937-1945; 1967-1985) é simplesmente uma retrogradação na manutenção e desenvolvimento da educação em todos os sentidos. 
Este dever promana diretamente da LDB e da lei n. 13.005/2014 na meta 2, estratégia 2.1; meta 3, estratégia 3.2 e meta 7 , estratégia 7.1 .

Como se sabe o currículo não é um campo neutro. Ele é uma campo de disputas. Na história dos Conselhos, a eles foi atribuída a tarefa de estabelecer a ordosub lege deste terreno essencial da educação. Se até 1988, todas as Resoluções relativas a esta matéria foram decididas à luz do currículo mínimo, após 1996 coube ao Conselho o estabelecimento de diretrizes para os componentes curriculares.

Ora, direitos e objetivos de aprendizagem e desenvolvimento próprio da BNCC, se apresentam como um tertius datur entre a rigidez de um currículo estabelecido desde a mais remota tradição legal e a amplitude das diretrizes curriculares nacionais.

Os direitos de aprendizagem e desenvolvimento apelam para o finalismo da cidadania e dos direitos humanos. Os objetivos já descem para um plano mais próximo do que se espera das etapas e modalidades da educação em termos de aprendizagem e de seu desenvolvimento.

Tarefa árdua, difícil, especialmente quando se sabe que o Brasil desenvolveu uma comunidade de especialistas em currículo, abriu a base nacional comum curricular para a consulta pública, ampliando o campo de disputas.

E aqui se situa a reflexão sobre os vinte anos da LDB com toas as mudanças e alterações que ela teve. Vale a pena discutir e propor seu redesenho ? Com o Congresso que temos, com um governo de facto disposto a deformar o financiamento da educação, reabrir a LDB para refazê-la não seria abrir uma "caixinha de pandora"?

\section{Conclusão}

Apesar de vários avanços alcançados, estes ainda não foram suficientes para cumprir os dispositivos constitucionais e legais de nosso ordenamento jurídico. A realidade educacional continua apresentando um quadro severo muito aquém dos benefícios que a educação desencadeia para o conjunto social e se encontra longe das promessas democráticas que ela encerra.

A LDB e o PNE nos põem diante de um desafio instaurador de um processo que amplia a democracia e educa para a cidadania, rejuvenesce a sociedade e irriga a economia.

Estamos diante da necessidade de uma saída urgente para uma educação de qualidade. Uma saída que obedeça aos ditames da razão que a educação inaugura. O Estado que não assume essa via decreta sua perdição. A Sociedade que não busca essa saída aceita a autoridade da submissão e refuga o caminho da autonomia.

Para sair de uma condição que nos constrange, em vários aspectos, a um confinamento educacional próprio do século 19, é preciso que a Sociedade e o Estado pactuem um novo esforço em prol da educação sem o qual não ultrapassaremos os limites dos avanços até agora celebrados. O futuro não espera! Só uma política de Estado que presentifique o potencial da educação será capaz de superar as contradições e as barreiras que impedem a construção de uma democracia mais ampla.

Se quisermos associar democracia e modernidade, ou o país como um todo toma a decisão inadiável e necessária de priorizar a educação básica como tarefa inadiável ou perderemos, todos, a velocidade da História. 


\section{Referências}

BELLONI, I. A educação superior na nova LDB. In: BRZEZINSKI, I. (Org.). LDB interpretada: diversos olhares se entrecruzam. São Paulo: Cortez, 2003.

BOBBIO, N. A Era dos Direitos.Rio de Janeiro : Campus, 1992.

. Teoria do Ordenamento Jurídico. Brasília : EDUNB, 1994.

BRITTO, V. L. A. Projetos de LDB: histórico da tramitação. in: CURY, C. R. J.; HORTA, J. S. B.;BRITO, V. L. A. Medo à Liberdade e Compromisso Democrático: LDB e Plano Nacional de Educação.São Paulo : Editora do Brasil, 1997.

BRZEZINSKI, I. (org). LDB Interpretada: diversos olhares se entrecruzam. São Paulo : Cortez, 2003.

BUENO, J. A. P. Direito público Brazileiro e Analyse da Constituição do Imperio. Rio de Janeiro : Typographia Imp. e Const. de J. Villeneuve E.C, 1857

BUFFA, E. Ideologias em Conflito: Escola Pública e Escola Privada. São Paulo: Cortez \& Moraes, 1979.

CARVALHO NETO, M. A sanção no procedimento legislativo. BeloHorizonte : Del Rey, 1992.

CASTRO, M. L. O. A Educação na Constituição de 1988 e a LDB. Brasília : André Quicé, 1998.

CATTANI, A.; OLIVEIRA, R. Constituições Estaduais Brasileiras e Educação. São Paulo : Cortez, 1993.

CHIZZOTTI, A. A Constituinte de 1823 e a Educação. In: FÁVERO, O. (org). A Educação nas Constituintes Brasileiras: 1823-1988.Campinas : Autores Associados, 1996

COUTO, C. G. A. Agenda constituinte e a difícil governabilidade. Lua Nova - Revista de Cultura e Política. 39: 33-52. São Paulo : CEDEC, 1997

CURY, C. R. J. Cidadania Republicana e Educação: Governo provisório do Mal. Deodoro e Congresso Constituinte de 1890-1891. Rio de Janeiro : DP\&A, 2001.

. A Educação na Revisão Constitucional de 1925-1926. Bragança Paulista : EDUSF, 2003.

A nova lei de diretrizes e bases da educação nacional: uma reforma educacional? In: ; HORTA,

J. S. B.;BRITO, V. L. A. Medo à Liberdade e Compromisso Democrático: LDB e PlanoNacional de Educação. São Paulo : Editora do Brasil, 1997.

. A Educação e a nova ordem constitucional. Revista ANDE, ano 8, n. 14, 1989, pgs. 5-11.

Educação e Normas Jurídicas pós - ConstituiçãoFederal de 1988. Universidade e Sociedade, ano

IV, n. 7, 1994, pgs. 33-35.

. Os fora-de-série na escola.Campinas: Associados, 2005.

. O Conselho Nacional de Educação (1931-1961): memória e funções. Pesquisa financiada pelo CNPq.

Relatório de 2013, p. 43. Trecho extraído do Livro de Atas do CNE, sessão de 27 de junho de 1931.

DEMO, P. A nova LDB: ranços e avanços. São Paulo : Papirus, 1997.

FARENZENA, N. A Política de Financiamento da EducaçãoBásica: rumos da legislação brasileira.PortoAlegre : UFRGS, 2006.

FÁVERO, O. (org). A Educação nas Constituintes Brasileiras: 1823-1988. Campinas: Autores Associados, 1996.

FRAUCHES, C. C. (org). LDB Anotada e LegislaçãoComplementar. Marília : Consultoria de Administração, 2000.

HORTA, J. S. B. O Hino, o Sermão e a Ordem do Dia: a educação no Brasil (1930-1945), Rio de Janeiro : UFRJ, 1994.

MALISKA, M. A. Direito à Educação e a Constituição.PortoAlegre : Sérgio Antonio Fabris, 2001

NAGLE, J. Educação e Sociedade na primeira República. São Paulo : EDUSP, 1974

NUNES, E. O. Educação Superior no Brasil: estudos, debates, controvérsias. Rio de Janeiro : Garamond, 2012.

RANIERI, N. B. Educação Superior, Direito e Estadona Lei de Diretrizes e Bases (Lei n. 9.394/96). São Paulo : Edusp/Fapesp, 2000.

SAVIANI, D. A Nova Lei da Educação: LDB, Trajetória, Limites e Perspectivas.Campinas : AutoresAssociados, 11a. edição, 2008.

. Educação Brasileira:estrutura e sistema. São Paulo : Saraiva, 1978

SILVA, J. A. Princípios do processo de formação das leis no direito constitucional.São Paulo: RT, 1964. 


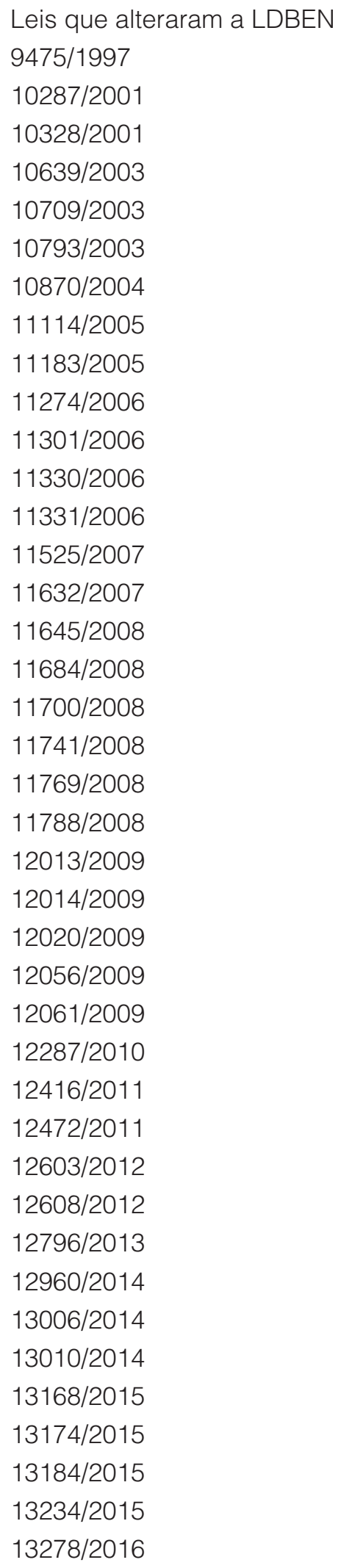

